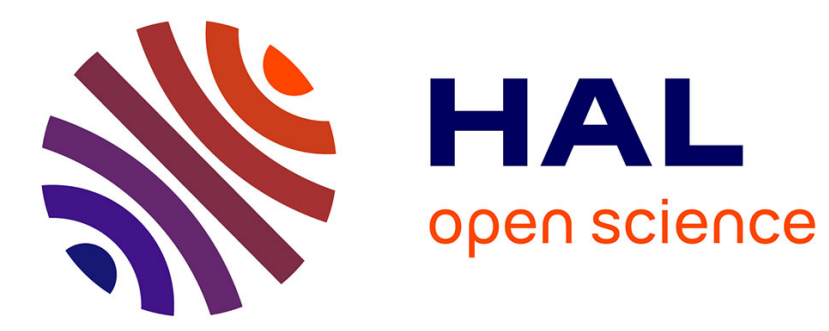

\title{
Optical Emission Analysis of a Si(CH3)4-Argon Radio Frequency Plasma for SiC Films Deposition
}

\author{
M. Andrieux, J. Badie, C. Bisch, M. Ducarroir, F. Teyssandier
}

\section{To cite this version:}

M. Andrieux, J. Badie, C. Bisch, M. Ducarroir, F. Teyssandier. Optical Emission Analysis of a $\mathrm{Si}(\mathrm{CH} 3) 4$-Argon Radio Frequency Plasma for SiC Films Deposition. Journal de Physique IV Proceedings, 1995, 05 (C5), pp.C5-607-C5-614. 10.1051/jphyscol:1995572 . jpa-00253934

\section{HAL Id: jpa-00253934 https://hal.science/jpa-00253934}

Submitted on 1 Jan 1995

HAL is a multi-disciplinary open access archive for the deposit and dissemination of scientific research documents, whether they are published or not. The documents may come from teaching and research institutions in France or abroad, or from public or private research centers.
L'archive ouverte pluridisciplinaire HAL, est destinée au dépôt et à la diffusion de documents scientifiques de niveau recherche, publiés ou non, émanant des établissements d'enseignement et de recherche français ou étrangers, des laboratoires publics ou privés. 


\title{
Optical Emission Analysis of a $\mathrm{Si}\left(\mathrm{CH}_{3}\right)_{4}$-Argon Radio Frequency Plasma for SiC Films Deposition
}

\author{
M. Andrieux, J.M. Badie*, C. Bisch, M. Ducarroir and F. Teyssandier \\ IMP-CNRS, Avenue de Villeneuve, 66860 Perpignan cedex, France \\ *IMP-CNRS, BP. 5, 66125 Font Romeu cedex, France
}

\begin{abstract}
A bst ract: RF glow discharges from tetramethylsilane diluted in an argon flow have been investigated in a cold wall R.F. (2MHz) P.E.C.V.D. reactor. This reactor is used for fast deposition of adherent amorphous silicon carbide films (with $\mathrm{Si} / \mathrm{C} \approx 1.2$ ) on steel. Optical emission from the plasma was sampled using a high resolution double monochromator ( $2 \mathrm{~m}$ focal length, 1800 grooves $/ \mathrm{mm}$ ) coupled with a multichannel CCD detector.

Only the lines corresponding to neutral or ionised Argon ( $\left.\mathrm{Ar}, \mathrm{Ar}^{+}\right)$, the broadened hydrogen Balmer $\left(\mathrm{H}_{\alpha}\right.$ et $\mathrm{H}_{\beta}$ ) and silicon ionised lines $\left(\mathrm{Si}^{+}\right)$were clearly pointed out perpendicularly or parallel to the discharge axis. The different broadenings observed were due to Doppler effects and connected with the movement of radical species. With TMS, the fine structure of the hydrogen line is deconvoluted in three gaussian like components, one of which denotes high energy atoms coming from a TMS derived species. Previous mechanisms for hot atom production do explain our results, but the various experimental broadenings could be ascribed to gradients in the cathode sheath adjacent to the substrate, and the hot atoms could be produced by electron impact on intermediate fragments, one bearing silicon, the other bearing carbon.
\end{abstract}

\section{INTRODUCTION.}

Plasma assisted CVD is an important process in growing films at low temperatures for materials production with a great potential for commercial applications; but as the result is strongly dependent on the created and transported active species, there exists, for a given atomic system, as many kinds of films as processes. Many laboratory studies have found some correlation between the input parameters and the films output characteristics; this is not enough to allow a scale up or a control of the process. For such goals one needs to understand the deposition mechanisms involved or at least to get a "signature of the deposit" that is the main species responsible for the composition of the deposit which, in most cases appears to be like an amorphous coating. However, for a complete understanding of such complex non equilibrium processes, many efforts have to be made to determine the local physical features $\left(\mathrm{T}_{e}, \mathrm{n}_{\mathbf{e}}, \mathrm{T}_{\mathrm{i}}, \mathrm{n}_{\mathrm{i}}, \mathrm{n}_{\mathrm{O}}\right.$ : respectively the electronic temperature and density, the ionic temperature and density, the neutral density) and the chemical ones (ions, neutral and excited species).

Previously, we have demonstrated the potential of silicon carbide based films of various compositions from tetramethylsilane argon mixtures, ranging from $\mathrm{Si} / \mathrm{C}=0.85$ up to 1.45 [1-3]. The purpose of the present work is to obtain qualitative information about the gaseous phase, close to the substrate, by spectroscopic emission to detect the excited species corresponding mainly to the most interesting experimental conditions: i.e. those leading to a deposit composition around $\mathrm{Si} / \mathrm{C}=1.2$ which exhibits the best adherence to a steel substrate due to an interaction layer [4].

TMS is a known silicon carbide precursor, but not of ten used. Some papers reported its decomposition in a radio frequency plasma and gave qualitative information about the radical species determined by mass spectrometry [5-6]. To the best of our knowledge, no data on excited species is currently available.

\section{EXPERIMENTAL SET UP.}

In this study, films were grown on a steel substrate (35CD4), using TMS/Ar mixtures in a cold wall electrodeless tubular vertical reactor (diameter $30 \mathrm{~mm}$, length $250 \mathrm{~mm}$ ). The substrate was grounded through an embedded thermocouple, and was heated at $850 \mathrm{~K}$ via an external water cooled coil connected to a radio frequency generator $(2 \mathrm{MHz})$. The substrate was located outside the coil which allowed the 
generation of the plasma. The flow rates were mass controlled, and total pressure was monitored by a gauge through a throttle valve. With such conditions, for a fixed input feed gas (TMS $=10 \%$ per vol), the deposit growth rates and compositions in function of deposition temperatures are summarized in figure 1.

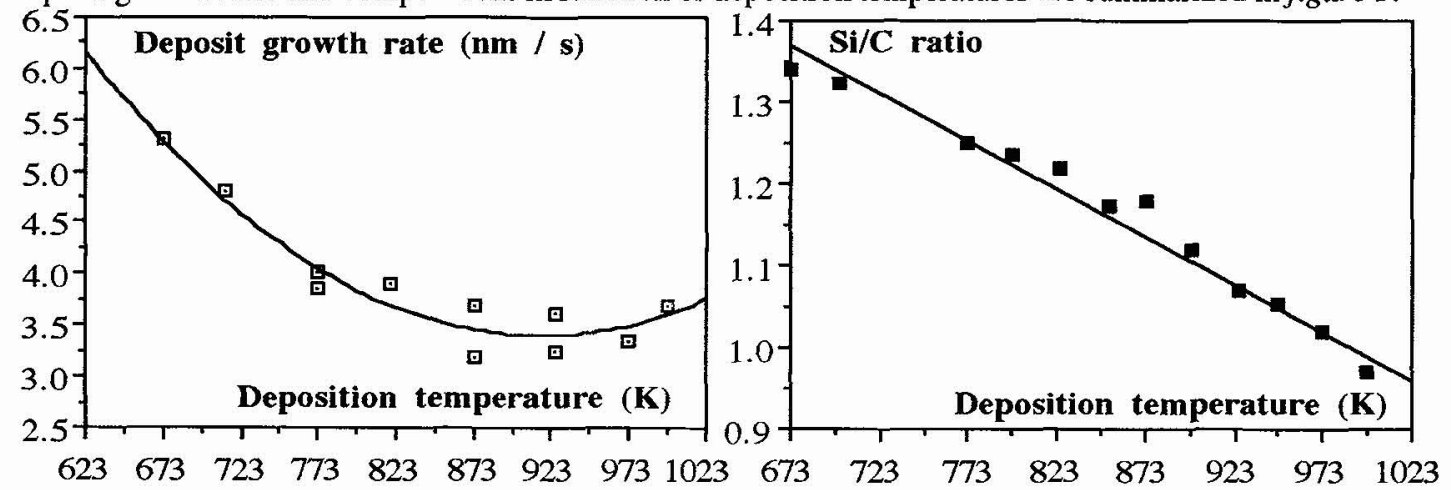

Figure 1: Deposition rate and $\mathrm{Si} / \mathrm{C}$ ratio versus temperature.

Figure 2 illustrates the global device used for the spectrometric examinations in various positions (A, B, C, $\mathrm{D}, \mathrm{X}$ ); optical emission is performed perpendicularly or parallel to the discharge axis. Spatially resolved measurements were made with an optical fiber (silica core of $200 \mu \mathrm{m}$, aperture 0.22) equipped with an afocal system (two lenses $f_{1}=19 \mathrm{~mm}, f_{2}=75 \mathrm{~mm}$ ) in order to collimate the emitted light. In such a way, the image source is four fold magnified; the micrometric displacement of this system in two directions allows analysis as a function of distance from the substrate. The $2 \mathrm{~m}$ focal length scanning double monochromator provides a spectral resolution of the order of $0.1 \AA$ at wavelengths of about $6500 \AA$, experimentally determined with a low pressure argon lamp. The light signals were detected with a CCD detector (515*385 cells) cooled with liquid nitrogen. A $25 \AA$ spectral field (in the wavelength range used in this study) is allowed by the 1800 grooves / mm gratings.

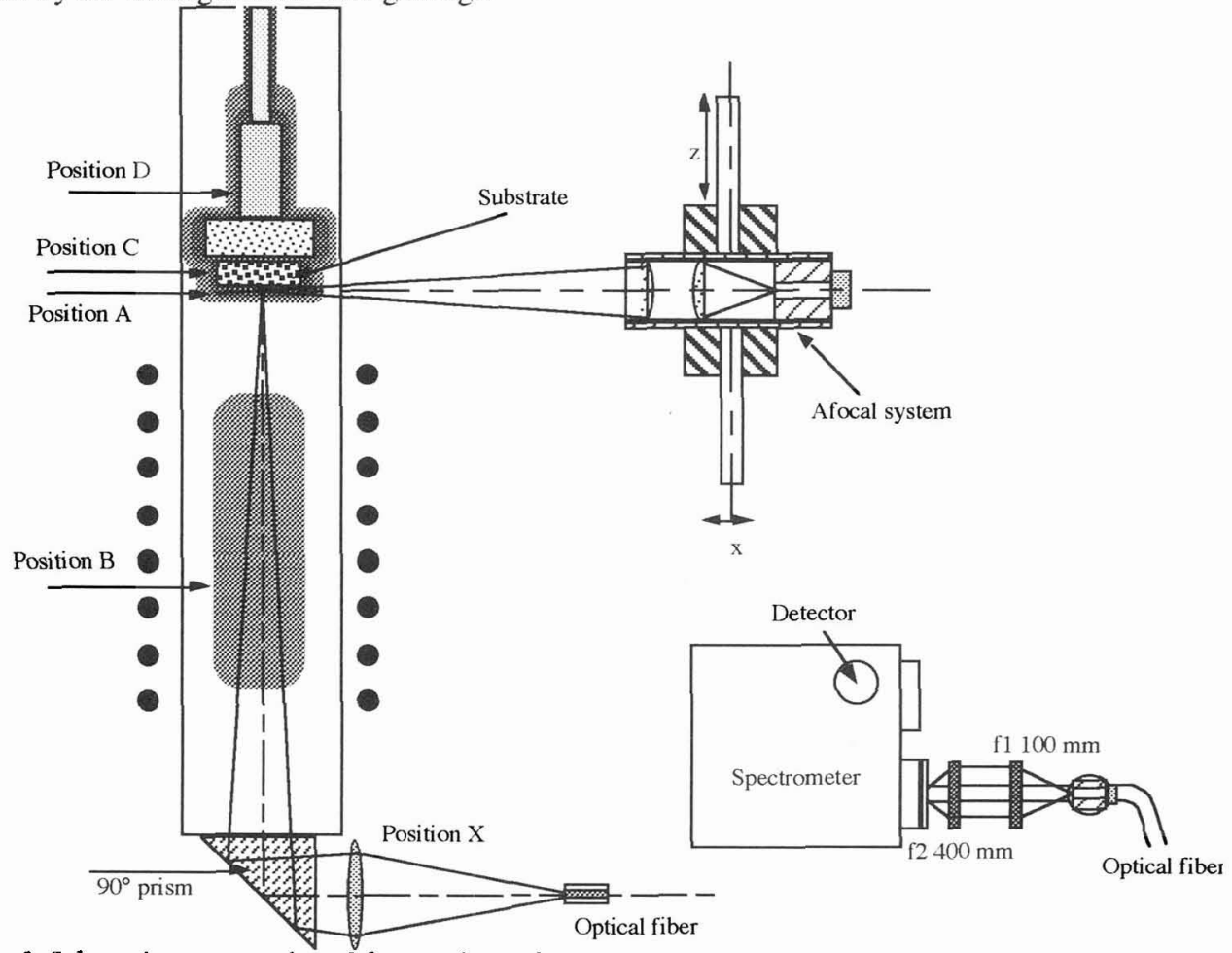

Figure 2: Schematic representation of the experimental system. 
Whatever the total pressure and the substrate-coil distance are, the glow discharge always looks the same. The glow discharge is constituted by a very luminous sheath surrounding the substrate ( that is the cathode sheath, negative glow, and collisional sheath), then a dark space, and inside the coil a less luminous volume corresponding to the positive column (figure 3 ).

When total pressure is increased, the glow discharge volume is affected: the cathode sheath around the substrate is restricted and the positive glow column tends to disappear. This configuration is likely to produce a situation in which active species would be discharged on the grounded substrate. The device, though inductively matched, probably corresponds in nature to a capacitive discharge, but nevertheless the substrate is not a cathode. In addition it is worth noting that the frequency used is the threshold value for which the electrons and ions can follow the temporal variations in applied potential [7-8]. The character of such a discharge raises basic questions on what occurs in the discharge and what are the potential and the electric fields. In such discharges, gas temperature are generally presumed to be in the range of of 1000 $2000 \mathrm{~K}$ [9].
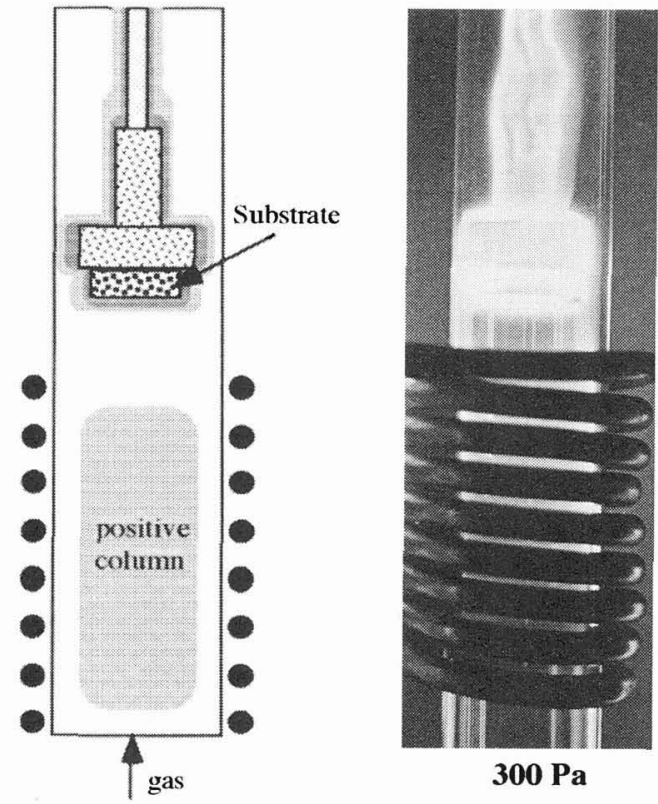

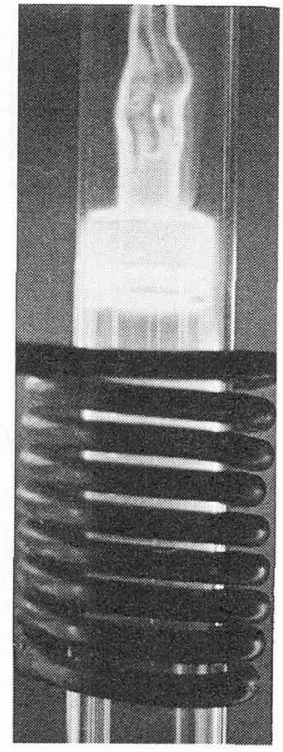

$800 \mathrm{~Pa}$

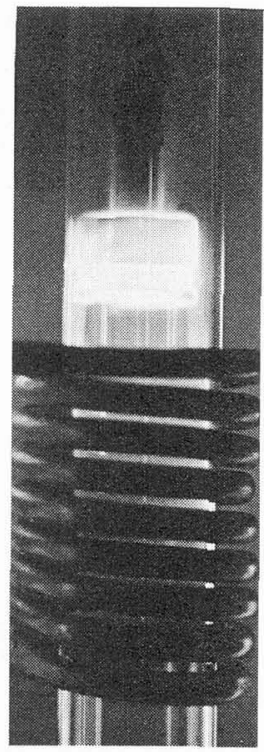

$1500 \mathrm{~Pa}$

Figure 3: Glow discharge at various pressures.

\section{EXPERIMENTAL RESULTS}

For all the experiments, an input gas mixture ( TMS flow rate $=0.51 / \mathrm{h}, 10 \%$ vol in Ar) was chosen. Various pressures and temperatures were investigated. However, because of the high deposition rate, the pollution on the reactor wall did not allow us to accumulate data for time up to ten minutes.

\subsection{Detected species.}

Optical investigation of the TMS-Ar discharge in the vicinity of the substrate showed that few spectral lines specific to the reactive elements are present. Apart from $\mathrm{Ar}, \mathrm{Ar}^{+}, \mathrm{H}_{\alpha}, \mathrm{H}_{\beta}, \mathrm{H}_{2}$, $\mathrm{Si}^{+}$, no other lines were detected (see table 1). The lines, that are mentioned in various previous studies of $\mathrm{SiH}_{4}$ and $\mathrm{CH}_{4}$ discharges [10-17] were not observed. In positions $\mathrm{B}, \mathrm{C}, \mathrm{D}$, intensities are too low to be accurately treated. Only the hydrogen and the silicon lines were able to caracterize the process when sampling perpendicularly or parallel to the axis (A and $\mathrm{X}$ positions). 


\begin{tabular}{|c|c|c|c|}
\hline Line & $\Delta \lambda(\AA)$ & Wavelength $(\AA)$ & detection \\
\hline \hline $\mathrm{H}_{\alpha}$ & $>0.3$ & 6562.80 & yes \\
\hline $\mathrm{H}_{\beta}$ & $>0.3$ & 4861.0 & yes \\
\hline $\mathrm{H}_{2}$ & $\approx 0.2$ & 6025.0 & yes \\
\hline $\mathrm{Si}^{+}$ & $\approx 0.5$ & 6347.1 & yes \\
\hline $\mathrm{Ar}$ & $\approx 0.1$ & $6663.9-6965.8$ & yes \\
\hline $\mathrm{Ar}+$ & $\approx 0.1$ & 6666.2 & yes \\
\hline $\mathrm{Si}$ & $\cdots-$ & $3905.52 \mathrm{et} 4102.94$ & no \\
\hline $\mathrm{SiH}$ & $\cdots$ & 4128.0 & no \\
\hline $\mathrm{SiC}_{2}$ & $\cdots-$ & 4977.4 & no \\
\hline $\mathrm{C}_{2}$ & $\cdots$ & 5415.9 & no \\
\hline $\mathrm{C}_{2}{ }^{-}$ & $\cdots$ & 4731.1 et 5165.2 & no \\
\hline $\mathrm{CH}^{+}$ & $\cdots-$ & $4314.2 \mathrm{et} 4324.0$ & no \\
\hline $\mathrm{CH}^{+}$ & $\cdots-$ & $3954.4 \mathrm{et} 4225.3$ & no \\
\hline $\mathrm{C}^{+}$ & $\cdots-$ & 6582.85 & no \\
\hline $\mathrm{C}$ & $\cdots--$ & 9658.49 & no \\
\hline
\end{tabular}

Table 1: Investigated species.

\subsection{Line shapes.}
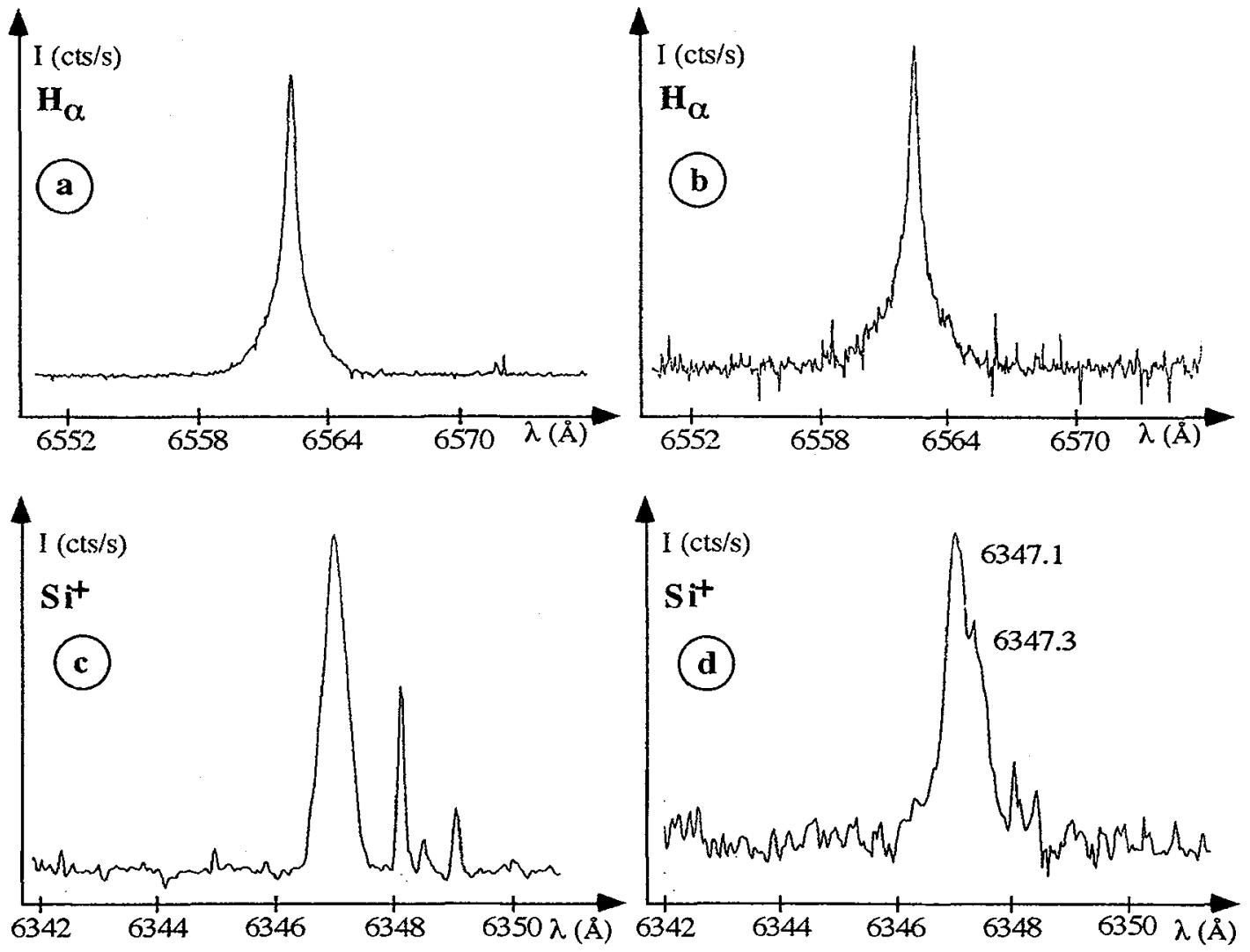


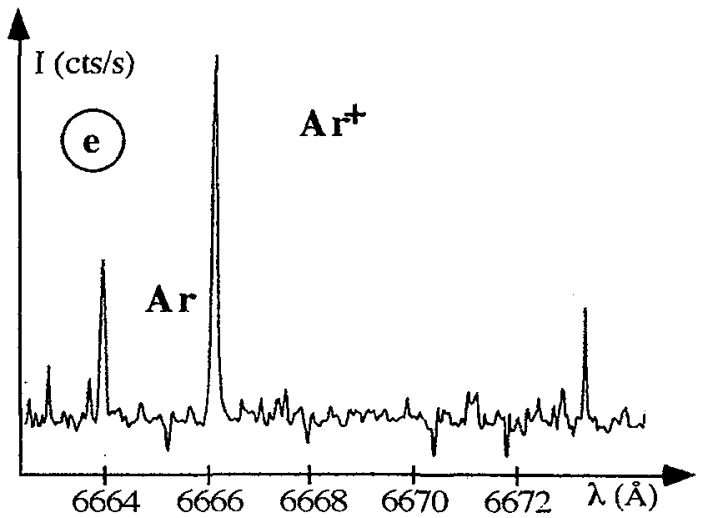

Figure 4: Emission lines for a TMS (10\%)-argon plasma at $853 \mathrm{~K}$ and $1100 \mathrm{~Pa}$ : a) $\mathrm{H}_{\alpha}$ in position $\mathrm{A}$, b) $\mathrm{H}_{\alpha}$ in position $\mathrm{X}$, c) $\mathrm{Si}^{+}$in position $\left.\mathrm{A}, \mathrm{d}\right) \mathrm{Si}^{+}$in position $\left.\mathrm{X}, \mathrm{e}\right) \mathrm{Ar}$ and $\mathrm{Ar}^{+}$in position $\mathrm{A}$ and $\mathrm{X}$.

A specific line shape, characterized by the broadening of the bottom part of the peak, was observed for the atomic hydrogen in every cases. Though less pronouced, this feature was also present in the silicon ion line. In contrast, such profile modifications were not detected in the Ar and Art lines. On the other hand, the optical sampling direction did not induce any modification of the various peaks (figure 4). The experiments carried out in pure argon or hydrogen-argon mixtures, furthermore confirmed these observations: the width of the argon spectral lines corresponded to the broadening resulting from the apparatus function $(0.3 \AA)$, while a broadening effect similar to that encountered in the previous case, was observed for the hydrogen lines (see table 1). The only difference when comparing those spectral lines with optical emissions in TMS-argon mixtures was that atomic hydrogen peaks were slightly broadened in this latter case.

\subsubsection{Study of the atomic hydrogen lines $\left(H_{\alpha}\right.$ at $6562.8 \AA, H_{\beta}$ at $\left.4861 \AA\right)$}

It is clearly seen in figure 5 that the peak shape is not dependent on the distance of the observation domain from the deposition surface. The peak intensity which is increasing when the distance to the surface diminishes, probably results from an increase of the secondary electron density. According to these observations, the broadening of the lines is attributed to a Doppler effect (because of the ratio of the peak width at half maximum (fwhm) of these lines $\left(\mathrm{H}_{\alpha}\right.$ and $\left.\mathrm{H}_{\beta}\right)$ which was equal to the ratio of the respective wavelengths).

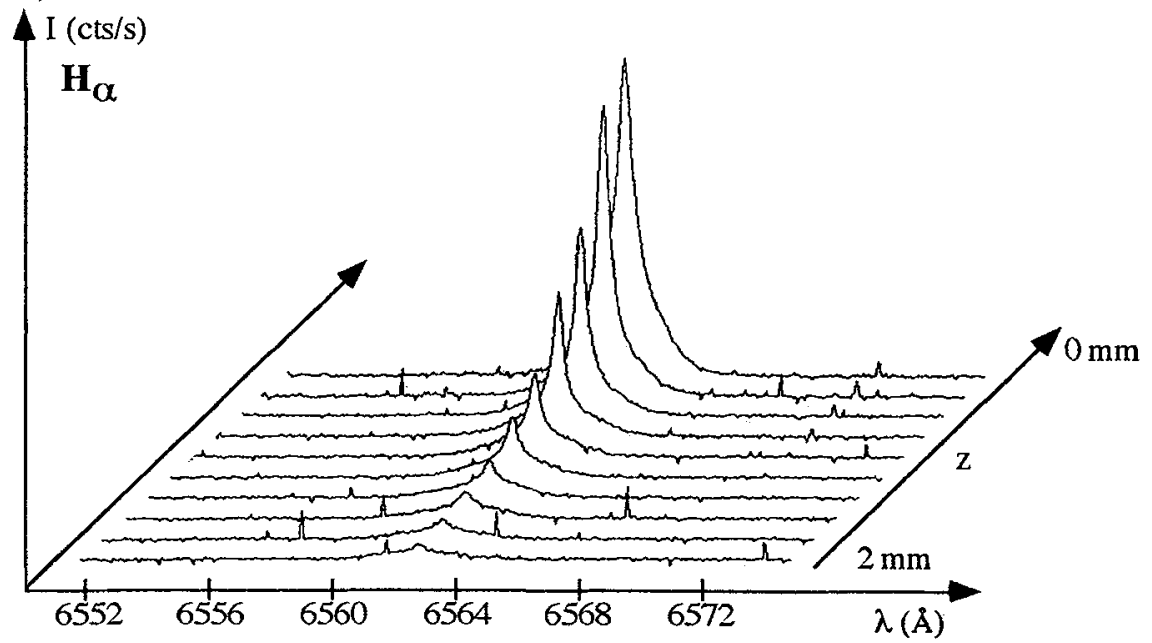

Figure 5: Evolution of the $\mathrm{H}_{\alpha}$ line as a function of the distance to the substrate (z) for an input mixture of $10 \%$ TMS in argon at $850 \mathrm{~K}$ and $1100 \mathrm{~Pa}$. 
A Voigt function was not able to fit the spectral profiles, but they were described satisfactorily by a combination of three gaussian components; a narrow component (NC, $0.3 \AA,<1 \mathrm{eV}$ ), and two broad components $\left(B_{1}\right.$ and $\left.B_{2}\right)$ with respective widths (fwhm) of $2.5-2.7 \AA(30-40 \mathrm{eV})$, and $0.7-0.8 \AA(7$ $-8 \mathrm{eV}$ ) (figure 6).

Note that in $\mathrm{Ar}-\mathrm{H}_{2}$ mixtures the observed profiles consist of two components $\mathrm{NC}$ and $\mathrm{BC}_{1}$ with two different kinetic energies as mentioned above. Thus, $\mathrm{BC}_{2}$ is the result of an excited $\mathrm{H}_{\alpha}$ fragment of an intermediate species coming from TMS.

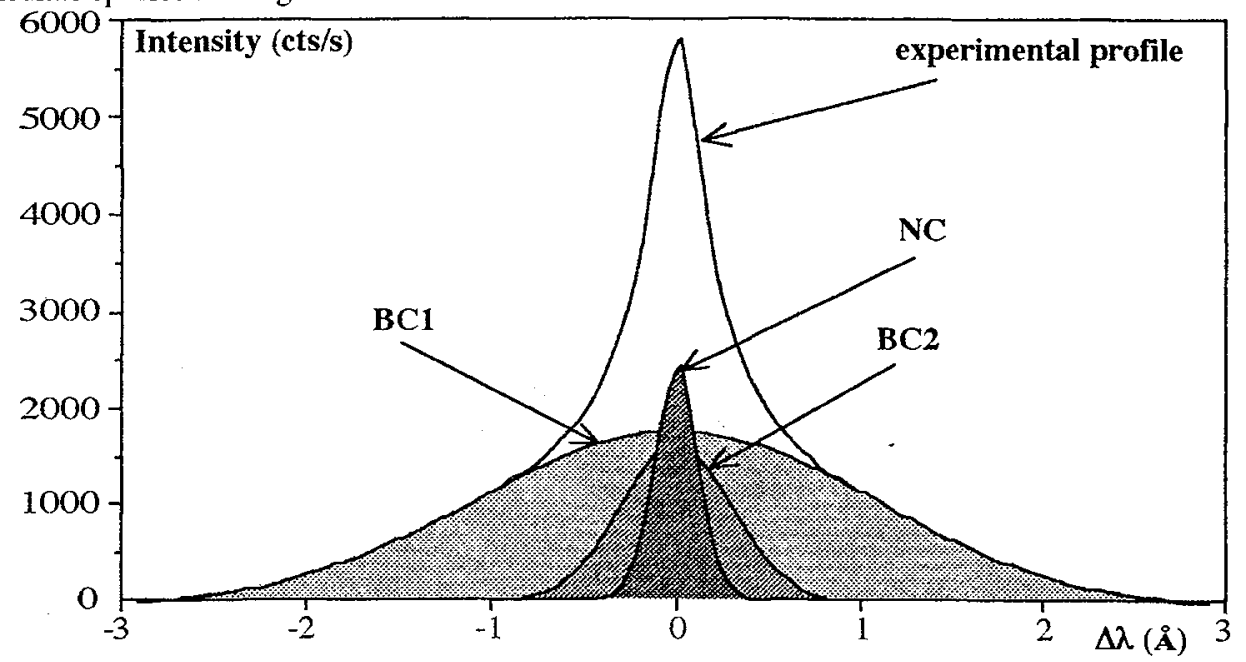

Figure 6: Typical deconvolution of a $\mathrm{H}_{\alpha}$ line (10\% TMS-argon mixture at $850 \mathrm{~K}$ and $1100 \mathrm{~Pa}$ ).

Several authors [18-22] reported similar line shapes in pure hydrogen, hydrogen diluted in helium, or pure methane glow discharges produced by different excitation processes (the total pressures were lower than $1.3 \mathrm{~Pa}$, and the hot hydrogen energies below $8 \mathrm{eV}$ ). These phenomena were usually explained by direct and/or pre dissociation processes implying Rydberg states. The presence of atoms of higher energy, like $\mathrm{BC}_{1}$ which was also observed previously in $\mathrm{DC}$ [23] or RF [24] discharges, was interpreted by mechanisms involving ions accelerated by the sheath fields.

\subsubsection{Study of the Si+ line.}

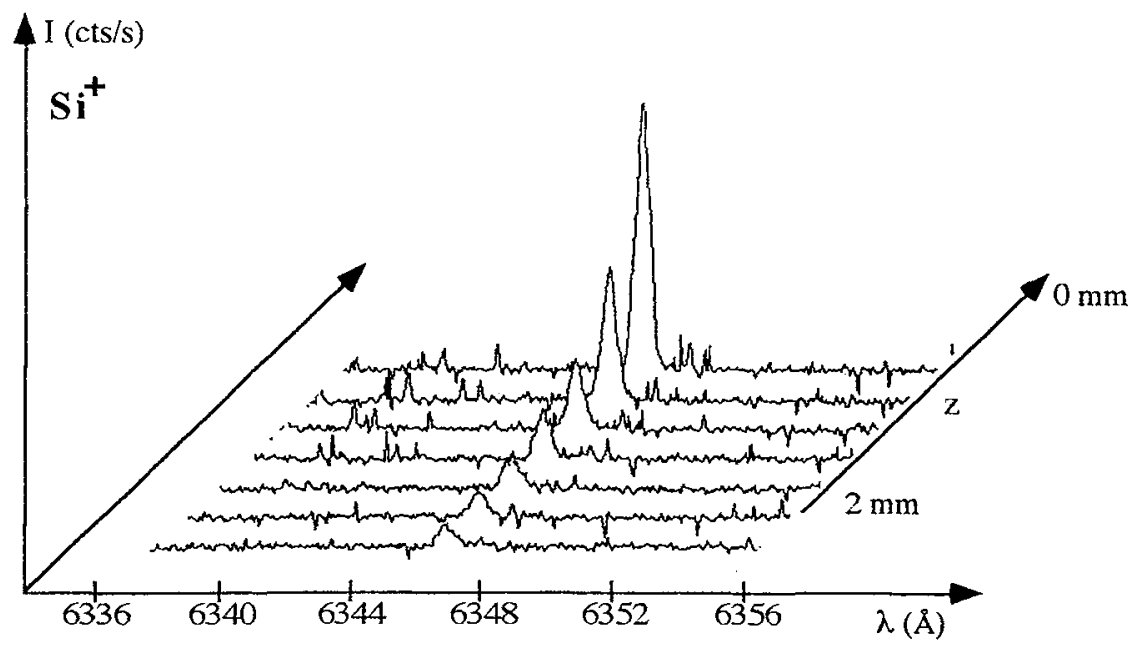

Figure 7: Evolution of the $\mathrm{Si}^{+}$line as a function of the distance to the substrate (z) for an input mixture of $10 \%$ TMS in argon at $850 \mathrm{~K}$ and $1100 \mathrm{~Pa}$. 
In all the conditions that were investigated, the line at $6371.9 \AA$ appears simultaneously with a peak located at $6347.1 \AA$. The emission intensities of both peaks were decreasing when the distance from the surface increased and vanished above $2 \mathrm{~mm}$. No change in the emission line shape was detected, but for all the results presented in figure 7 the constant fwhm remains around $0.5 \AA$, that results in an anomalous average kinetic energy of the silicon ion (around $20 \mathrm{eV}$ ) with respect to the $\mathrm{Ar}^{+}$line. These variations are clearly observed in figure 4, when comparing b-e and d-e for parallel or perpendicular optical samplings. On the other hand, a red wavelength shift was detected on $d$, which is indicative of silicon ions moving towards the substrate. These features are expected to be characteristic of the deposition process.

\section{4- DISCUSSION AND TENTATIVE INTERPRETATION.}

Two species due to the TMS precursor were unambiguously identified but their emission line shapes raise the question of the mechanisms which could be responsible for the Doppler broadening. All the measurements show that the line widths are depending on the spatial sampling of the light (figure 8). This can be interpreted in terms of more or less acceleration of the species. Such behavior was previously reported by C. Barbeau [23] in DC hydrogen glow discharge at pressures lower than $76 \mathrm{~Pa}$.

For atomic hydrogen, the $\mathrm{NC}$ and $\mathrm{BC}_{2}$ components could be explained by mechanisms involving molecule surexcitation processes as proposed by R.S. Freund [22], but our $\mathrm{BC}_{1}$ component corresponds to a higher energy $(30 \mathrm{eV}$ instead of $6 \mathrm{eV}$ ). Hence, the reactions which produce $\mathrm{H}$ atoms in excited states cannot correspond to Freund's ones.

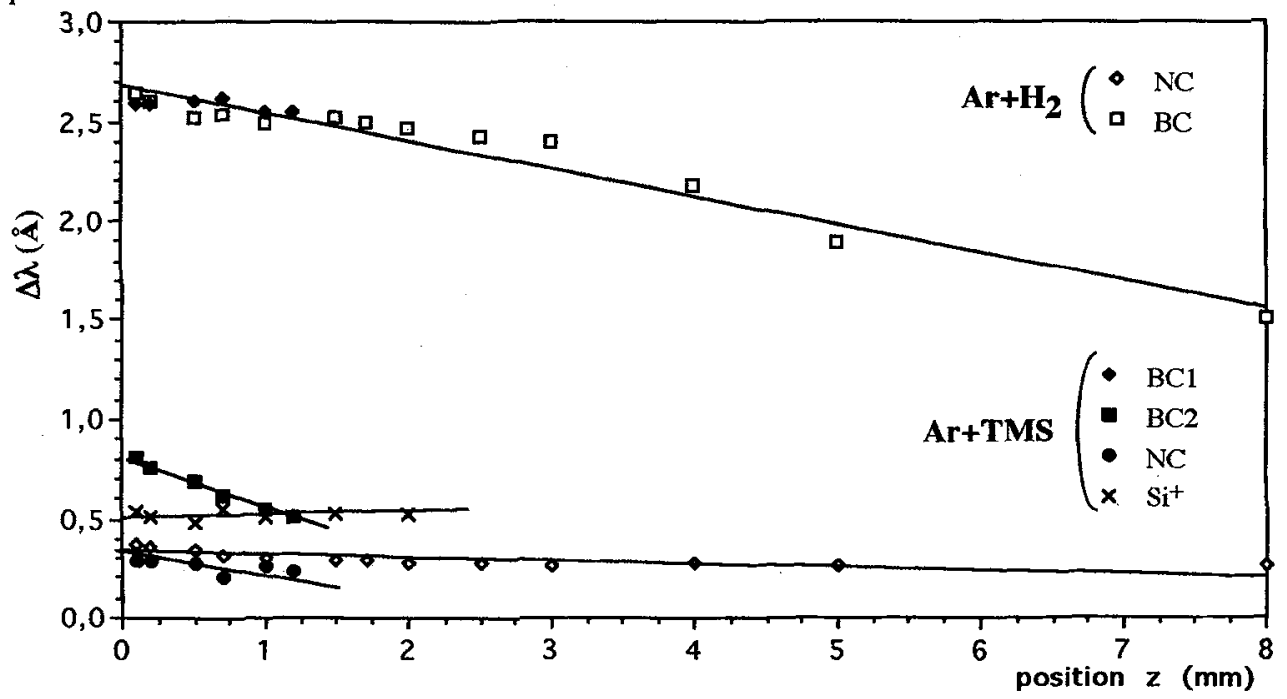

Figure 8: fwhm of the various components of $\mathrm{H}_{\alpha}$ and $\mathrm{Si}^{+}$line $(10 \%$ TMS-argon mixture at $853 \mathrm{~K}, 1100 \mathrm{~Pa})-(20 \%$ hydrogen-argon mixture at $853 \mathrm{~K}$ and $1300 \mathrm{~Pa}$ ).

An interpretation based on mechanisms involving hydrogen ions $\mathrm{H}^{+}, \mathrm{H}_{2}^{+}, \mathrm{H}_{3}^{+}$(proposed by C. Barbeau [23]) could explain high energy components and furthermore, as mentioned by this author, the hydrogen line exhibits a noticeable broadening with wings extending to a shifted wavelength (the blue wing represents excited species coming from the surface and the red wing those going towards the surface). In our case, the sampling in $\mathrm{X}$ position (figure $4 \mathrm{c}$ ) does not allow the observation of such wings that occur in a higher operating range of pressure. However the line structures of $\mathrm{H}_{\boldsymbol{\alpha}}$ are basically different in the $\mathrm{A}$ and $X$ positions. It is worthwhile to mention that lateral wings begin to appear under $1300 \mathrm{~Pa}$ in the hydrogenargon mixture. Such mechanism which is based on electronic collisions with molecular hydrogen is unable to account for the presence of high energy silicon ions. Moreover collisional exchanges with argon and/or its low energy ions have to be ignored to explain particles energies of about $20-40 \mathrm{eV}$ (on the basis of simple calculations on energy transfer in an elastic collision).

On the base of the different behaviour of $\mathrm{Ar}^{+}$and $\mathrm{Si}^{+}$species (which have quite similar atomic weights) (see figure 4) an acceleration mechanism in the cathode electric field cannot take place. One could think of charge exchange reactions in relation with secondary emission from the substrate, but such a mechanism do 
not take into account the different ions energies. Furthermore, the both mechanisms should influence also the argon species.

Besides these considerations on possible mechanism which do not fit the experimental data, the observation of both figure 3 and figure 8 may suggest a simpler interpretation hereafter detailed. Figure 3 reveals a glowing layer close to the substrate which can be considered as a boundary layer and figure 8 indicates variable kinetic energies for species in this zone. Due to the steady state deposition regime of the process, the fluxes of species ( $\mathrm{Ji}$ ) have to be constant. Since the flux is the product of the state density multipled by the mean velocity, any change in the velocity relates to an opposite variation of the state density. Therefore, figure 8 would indicate concentration gradients. Recent equilibrium calculations on the system Si-C-H taking into account organosilicon species and radicals in particular [25], demonstrated the ability of the carrier gas to change the population of radical species assuming homogeneous equilibrium. As an example, for an input composition corresponding to the silicon on carbon ratio in TMS, under reduced pressure and above $1000 \mathrm{~K}$, the main bearing silicon species are $\mathrm{Si}_{2} \mathrm{C}$ and $\mathrm{SiC}_{2}$, whereas the main bearing carbon species are $\mathrm{C}_{2} \mathrm{H}_{2}$ and $\mathrm{CH}_{4}$. Furthermore, the amounts of $\mathrm{C}_{2} \mathrm{H}_{2}$ and $\mathrm{SiC}_{2}$ tend to decrease when lowering temperature while the amounts of $\mathrm{Si}_{2} \mathrm{C}$ and $\mathrm{CH}_{4}$ tend to increase. As the substrate temperature is lower than the temperature of the gas layer that surrounds it, one can assume that such species could be accelerated in accordance with the flux conservation, leading by electron impact to the observed high energy

fragments $\mathrm{H}^{*}$ ( component $\mathrm{BC}_{2}$ ) and $\mathrm{Si}^{+}: \begin{aligned} & \mathrm{C}_{2} \mathrm{H}_{2}+e \rightarrow 2 \mathrm{C}+\mathrm{H}^{*}+H \\ & \mathrm{SiC}_{2}+e \rightarrow 2 \mathrm{C}+\mathrm{Si}^{*}\end{aligned}$

At the same time, the argon carrier gas flux remains constant and therefore the emission lines of $\mathrm{Ar}$ and $\mathrm{Ar}^{+}$ excited by the same process are not broadened.

In summary, optical emission measurements close to the substrate yield information on the moving radicals through the analysis of line shapes. Work is currently in progress to confirm or refine the proposed mechanism. High energy species $\left(\mathrm{H}^{*}\right.$ and $\left.\mathrm{Si}^{+}\right)$could be a useful mean of controlling the process (if variations are correlable with the deposit rates and compositions which are known to vary with the deposition temperatures).

\section{References:}

[1] Lelogeais M. and Ducarroir M., Thin Solid Films, 197 (1991) 257-267.

[2] Lelogeais M. and Ducarroir M., Surf.Coat.Technol., 48 (1991) 121-129.

[3] Agullo J.M., Ducarroir M., Clemendot F. and Lina A., Proc. of the IX Euro.Conf. on CVD,Tampere Finland, Mäntylä T. (Ed)Colloque C3 Journal de Physique Suppl. N8, (1993) 163-170

[4] Lelogeais M., Ducarroir M. and Berjoan R., Proc. of the VIII Euro. Conf. on CVD, Glasgow U.K., Hitchman M.L., Archer N.J. (Eds)Colloque C2 Journal de Physique Suppl. N7, (1991) 601-608

[5] Kim D.S. and Lee Y.H., J.Electrochem.Soc., 141 (12) (1994) 3562-3571.

[6] Rynders S.W., Scheeline A. and Bohn P.W., J.Appl.Phys., 69 (5) (1991) 2951-2960.

[7] Chapman B., Glow discharge processes, Wiley-Intersicence Publication (1980)

[8] Reif R. CVD Abstracts personnal communication.

[9] Inspektor A.K., Surf.Coat.Technol., 33 (1987) 31-48.

[10] Weiler M., Kleber R., Jung K. and Ehrhardt H., Diamond and Related Materials, 1 (1992) 121-126.

[11] Fantoni R., Giorgi M., Moliterni A.G.G., Berden W.C.M. and Lazic V., J.Mater.Res., 7 (5) (1992) 1204-1214.

[12] Gomez-aleixandre G., Sanchez O., Castro A. and Albella J.M., J.Appl.Phys., 74 (6) (1993) $3752-$ 3757.

[13] De la cal E., Tafalla D. and Tabares F.L., J.Appl.Phys., 73 (2) (1993) 948-954.

[14] Yoshimoto M., Aizawa K., Fuyuki T., Matsunami H., Jpn.J.Appl.Phys., 25 (10) (1986) 1465-1469.

[15] Hicks S.E. and Gibson R.A.G., Plasma Chem.Plasma Process., 11 (4) (1991) 455-472.

[16] Banerjee A. and Debroy T., J.Vac.Sci.Technol.,A, 10 (6) (1992) 3395-3400.

[17] Meeusen G.J., Ershov-pavlov E.A., Meulenbroeks R.F.G., Van de sanden M.C.M. and Schram D.C., J.Appl.Phys., 71 (9) (1992) 4156-4163.

[18] Ito K., Oda N., Hatano Y. and Tsuboi T., Chem.Phys., 17 (1976) 35-43.

[19] Ito K., Oda N., Hatano Y. and Tsuboi T., Chem.Phys., 21 (1977) 203-210.

[20] Nakashima K., Taniguchi M. and Ogawa T., Chem.Phys.Lett., 197 (1-2) (1992) 72-76.

[21] Hatano Y, Dynamics of excited molecules vol 82 (Elsevier Science, K. Kushitsu, 1994) pp 151-216.

[22] Freund R.S., Schiavone J.A. and Brader D.F., J.Chem.Phys., 64 (3) (1976) 1122-1127.

[23] Barbeau C. and Jolly J., J.Phys.D, 23 (1990) 1168-1174.

[24] Cappelli A., Gottscho R.A. and Miller T.A., Plasma Chem.Plasma Process., 5 (1985) 317-331.

[25] Allendorf M.D., J.Electrochem.Soc., 140 (3) (1993) 747-753. 